\title{
Competencias de enfermería para el trabajo con Donantes Potenciales de Órganos (DPO). Estado del arte.
}

\section{Nursing competences for work with Potential Organ Donors (DPO). State of art}

\author{
Hernández-Ortiz, Adonis Faustino ${ }^{1 *}$ \\ ${ }^{1}$ Universidad Estatal Península de Santa Elena \\ *adonishernandez7213@gmail.com
}

DOI: https://doi.org/10.26871/killcana_salud.v2i1.275

\begin{abstract}
Resumen
Contexto: Durante los últimos años, el mundo ha presenciado grandes avances en la tecnología del trasplante de órganos, entendido como el procedimiento médico el cual se extraen tejidos de un cuerpo humano y se reimplantan en otro con el propósito de que el tejido trasplantado realice su nueva localización la misma función que realizaba previamente. La labor del trasplante no comienza en el acto mismo de sustituir un órgano por otro, sino que previo a ese paso, existen otros no menos importantes, que deben ser observados por los donantes y el personal de enfermería que recibe a los pacientes DPO. Las competencias que deben tener los enfermeros y enfermeras para realizar dicha labor, deben ser formadas desde las carreras, para poder insertarse exitosamente en cada paso del complejo proceso de salvar un órgano vital o un tejido para su trasplante. Objetivo: En este artículo, de corte bibliográfico, se enuncia como objetivo, actualizar el estado del arte sobre la temática para poder incorporar contenidos al currículo y a la formación de la licenciatura en Enfermería.
\end{abstract}

Palabras clave: Donante Potencial de Órganos; competencias profesionales, enfermería.

\begin{abstract}
Context: Over the past few years, the world has witnessed great advances in organ transplant technology- a medical procedure in which the tissue is removed from one human body and re-implanted into another, so that the transplanted tissue can perform in its new location, the same function it did before. The transplant does not start with the replacement of one organ by another, there are other steps of no less importance prior to that, which must be observed by both, the donors and the nurses who receive "DPO" patients. The skills that nurses must have in order to perform this task must be developed in their careers, so that they can be successfully implemented into every step of the complex process of saving the vital organ or the tissue to be transplanted. Objective: The objective of this bibliographic article is to update the state of the art on this subject, in order to include contents to the curriculum and in nursing education.
\end{abstract}

Key words: Organ Potential Donor; professional skills, nursin .

\section{Introducción}

La problemática actual de la donación de órganos constituye un elemento de polémica en el mundo, aun cuando la mayoría piensa que resulta positivo salvar vidas a partir de un trasplante de órganos o tejidos.

En el caso concreto de Ecuador, en el año 2017 hubo un total de 173 donantes. Su composición, se aprecia en la tabla No. 1.

Tabla 1. Donantes de órganos en 2017

\begin{tabular}{|c|c|c|}
\hline \multicolumn{3}{|c|}{ Donantes de órganos, al fallecer, 2017 en Ecuador } \\
\hline Mujeres & Hombres & Total \\
\hline 105 & 68 & 173 \\
\hline \multicolumn{3}{|c|}{ Edad promedio 39 años } \\
\hline
\end{tabular}

Fuente: Informe de rendición de cuentas INDOT 2017
Según el Instituto Nacional de Donación y Trasplante de Órganos, Tejidos y Células (INDOT), perteneciente al Ministerio de Salud Pública, en su informe anual de rendición de cuentas, refiere que los donantes contaban con una edad promedio de 39 años. Tuvieron lugar 150 trasplantes renales, de ellos 9 de personas vivas y el resto de fallecidos. Tuvieron lugar 37 trasplantes hepáticos, y 420 de córnea.

Esta situación que cada día se incrementa en el país, necesita de una formación en enfermería que permita enfrentar esta situación, que requiere cuidados complejos, con una formación profesional que facilite una eficiencia total en esta vía para salvar vidas.

Es por ello que a partir de búsquedas bibliográficas y de la propia experiencia del autor, se emiten estas consi- 
deraciones con el fin de sensibilizar y proponer contenidos mínimos que el personal de enfermería debe conocer desde el punto de vista técnico procedimental y ético- actitudinal ante este fenómeno.

\section{Desarrollo}

El reemplazo de órganos tuvo sus orígenes desde tiempos remotos,.Hoy día es un acto rutinario que restaura la salud y reincorpora al individuo a la sociedad.

Los primeros intentos en cirugía plástica están muy ligados al comienzo de la práctica del trasplante. El primero en desarrollar esta actividad fue Sushruta, hace más de 2500 años en el norte de la India, donde recibe el crédito por haber usado injertos de piel en la reparación de narices perdidas en batallas y a mutilados en castigo por crímenes, aunque no exista testimonio real acerca del éxito de estos procedimientos. El inicio de la era moderna, es atribuido al cirujano boloñés Gaspare Tagivacozzi (1545-1599). Su obra clásica de la cirugía de mutilación por injerto describió lo que más adelante sería conocido como colgajo de antebraz, al adherir un colgajo de piel del antebrazo a la nariz y cortar la conexión algunas semanas más tarde. El primer trasplante renal lo llevó a cabo un cirujano ucraniano en 1954 quien trasplantó un riñón de un hombre de 60 años a una joven de 26 años en coma urémico luego de un intento de suicidio, aunque la operación fue fallida constituyó un cambio, un avance significativo en el campo del trasplante.

En Latinoamérica, Cuba se sitúa a la vanguardia en este campo, pues en 1970 se inician en el Instituto de Nefrología los trasplantes renales haciéndose extensiva a otras provincias debido a las necesidades que imperaban en ese momento; en 1985 se introducen la realización de otros trasplantes de órganos sólidos como corazón, pulmón, y páncreas. En 1993 comienza a desarrollarse la donación de órganos de donante cadáver con sostén en el Hospital Universitario "Gral. Calixto García" y en ese mismo período se inicia con el diagnóstico de la muerte cerebral y el mantenimiento del donante en la UCI.

La muerte encefálica (ME) definida por Parrilla et $\mathrm{al}^{1}$ como el cese completo e irreversible de todas las funciones del cerebro entero, incluido el tronco cerebral, los hemisferios cerebrales y el cerebelo surge con el desarrollo de los cuidados intensivos y el uso de los medios de soporte circulatorio y respiratorio en la sustitución de funciones vitales lo que posibilitó el mantenimiento del donante, y la protección de los órganos a trasplantar.

Diversos estudios epidemiológicos ${ }^{2}$ han constatado que alrededor del $14 \%$ de los pacientes que fallecen en las Unidades de Cuidados Intensivos (UCI) lo hacen en situación de ME lo que significa que esos casos recibieron mantenimiento hemodinámico.

Se ha evidenciado que en el paciente con ME ocurren una serie de cambios fisiopatológicos en prácticamente todos los sistemas del organismo, siendo las alteraciones a nivel cardiovascular y respiratorio conjuntamente con los desórdenes hidroelectrolíticos las alteraciones más importantes a tener en cuenta, que de no ser prevenidos y/o tratados enérgicamente llevarían a la isquemia celular y en un período no mayor de 48 - 72 horas a la parada cardiaca.

El conocimiento de que la principal causa de disfunción primaria del injerto es el mal manejo del donante, hacen que se tomen todas las medidas necesarias dirigidos a corregir las alteraciones que pudieran surgir durante el mantenimiento con el fin de preservar la viabilidad de los órganos a trasplantar.

El personal de enfermería en la UCI juega un papel protagónico, requiere de una intensa dedicación durante las horas que dure el proceso, los esfuerzos deben estar dirigidos a mantener al "cadáver latente" en condiciones óptimas de oxigenación y perfusión para intentar un funcionamiento adecuado de los demás órganos con vistas a mantenerlos viables y útiles para su posterior implante. Muñoz ${ }^{3}$ refiere que las acciones de enfermería que se le aplican están basadas en las seis necesidades básicas para todo paciente crítico según el modelo de Virginia Henderson y son: respiración, eliminación, mantenimiento de la temperatura corporal, necesidades de hidratación y nutrición, necesidades de seguridad y protección de los valores humanos del cadáver.

Por ello es menester que los estudiantes de enfermería desde su formación profesional conozcan que:

- La meta fundamental en el mantenimiento del potencial donante es estabilizar la hemodinámica para mantener una perfusión tisular adecuada y garantizar una entrega de oxígeno óptima, también es indispensable la corrección de la temperatura, diabetes insípida, alteraciones hidroelectrolíticas $\mathrm{u}$ otras alteraciones fisiopatológicas que se presentan como consecuencia de la ME.

- Se debe mantener un monitoraje hemodinámico continuo y una vigilancia estrecha de las funciones respiratoria y renal, así como de la temperatura corporal, además de mantener un control sobre la hemoglobina y los electrolitos (Ramos Peña et al), ${ }^{4}$ implicando un arduo accionar en las intervenciones de enfermería, de modo que debe demostrarse la importancia de los cuidados de enfermería en el mantenimiento del donante potencial garantizando la calidad de órganos para el futuro trasplante.

- Cuando se diagnostica la ME, los esfuerzos para mantener la vida del paciente y preservar su actividad cerebral concluyen, los cuidados del enfermo se convierten en medidas de mantenimiento del donante, por tanto, el equipo multidisciplinario de salud que realiza esta actividad debe asegurar un correcto mantenimiento del donante de órganos para evitar la pérdida de los mismos, de los cuales depende la vida de pacientes en lista de espera y para que los órganos se encuentren en el mejor estado posible hasta que sean transferidos al receptor. 
- $\quad$ Este trabajo de mantenimiento se realiza en un tiempo medio de 5-8 horas, en este periodo de tiempo los coordinadores de trasplante desarrollan las acciones pertinentes para hacer viable la donación, extracción y posterior implante, obtención de consentimiento familiar, validación y evaluación de idoneidad de los órganos, identificación de receptores y coordinación del implante así como la coordinación con los diferentes equipos extractores e implantadores. Los médicos y enfermeros de la UTI son piezas claves del equipo multidisciplinario que desde la cabecera del donante y de forma ininterrumpida llevan a cabo técnicas, cuidados y atenciones específicas necesarias para conseguir la preservación, oxigenación y perfusión de los órganos en las mejores condiciones posibles.

- Las patologías que con mayor frecuencia conducen a la ME son el TCE (40 - 60\%), Enfermedad Cerebro Vascular (ECV 30 - 45\%), Encefalopatía Anóxica (EA8 $10 \%)$ Tumor Cerebral Primario (TCP) $(2-4 \%)$.

- La identificación y selección del posible donante conlleva a una exhaustiva valoración clínica del paciente por parte del médico para evaluar su idoneidad que incluye el establecimiento de la causa de la muerte, revisión de la historia clínica con el análisis de antecedentes patológicos personales y contraindicaciones para la donación, evaluación de la perfusión y oxigenación tisular y determinaciones analíticas y pruebas complementarias, así como la valoración del Nefrólogo y Oftalmólogo.

- El trasplante se convirtió en una práctica cotidiana en muchos hospitales del mundo debido los avances científicos técnicos, organizativos y administrativos, existe cada vez mayor número de pacientes que tienen acceso a esta modalidad terapéutica. Sin embargo su utilización está limitada por la baja disponibilidad de órganos para trasplante, entre otras razones, por la falta de sensibilización y conocimiento de donantes, lo que significa un nuevo reto para las carreras de enfermería.

- La poca disponibilidad de órganos ha traído como consecuencia que se intenten todos los medios para detectar a los pacientes que fallecen en situación de muerte cerebral teniendo en cuenta que para el desarrollo de los diferentes programas de trasplante es necesaria la existencia de un programa paralelo de obtención de órganos y tejidos, donde el pilar fundamental es el procesos de donación.

\section{Consideraciones éticas de la Donación de Órganos}

La ética y moralidad se imponen como regla fundamental en todas las actividades de los profesionales relacionada con la donación y el trasplante de órganos, las actitudes de los profesionales que intervienen en todo el proceso, deben estar acordes con planteamientos éticos claros y objetivos. En primer lugar hay que contar con el consentimiento informado de los pacientes, lo cual influye en el signo ético que se le atribuye al acto, además de que está en concordancia con principios, morales, religiosos, etc, de quien dona.

Una vez conocido el consentimiento del DPO, la atención que la enfermería aplica al donante potencial de órganos son primordiales, (Ríos et al) ${ }^{5}$ encaminados a conseguir el mantenimiento de buena función en el máximo número de órganos y poder así trasplantarlos con éxito. Estos son: cuidados de enfermería en el mantenimiento de la función cardiovascular, de la función respiratoria, en la termorregulación, equilibrio hidroelectrolítico y de la función endocrino metabólica, de la coagulación, cuidados de enfermería de la función renal, en el mantenimiento de las córneas, y para la prevención de la infección, entre otros.

El control del duelo disfuncional y el sufrimiento de la familia, forman parte de las acciones de enfermería encaminadas a satisfacer la necesidad de protección de los valores humanos del paciente trabajo de enfermería, la enfermera siempre ha de proteger los valores humanos del paciente.

En referencia a lo sociocultural Vélez, ${ }^{6}$ refiere que entre los fenómenos socioculturales que más influyen sobre la donación destacan: culto al cuerpo, desconocimiento del concepto de muerte cerebral, tráfico de órganos, miedo irracional a las nuevas tecnologías, inmigración y racismo... Mayor información y un trato más sensible se apuntan como factores facilitadores y de compensación social en la donación de órganos.

Estos conceptos deben estar en la base del trabajo de intervención de enfermería para sensibilizar sobre la importancia de donar órganos, sin descuidar las creencias y la cultura de cada DPO.

\section{Cuidados y procedimientos propios de la enfermería en casos específicos de DPO}

La monitorización de las constantes vitales: electrocardiograma continuo, tensión arterial, presión venosa central, diuresis, gasometría arterial y la pulsioximetría son elementos importantes, pues la destrucción del encéfalo determina la pérdida absoluta de la homeostasia del donante. La colocación de un catéter intraarterial garantizará un chequeo más específico de la tensión arterial y facilitará la extracción de la sangre para valoraciones gasométricas: el cateter venoso central una vez insertado facilita la medición de la presión venosa central, la sonda vesical un registro continuo de las características y cantidad de la orina, la temperatura debe medirse de forma central.

Según Monpeller et $\mathrm{al}^{7}$ los cuidados de enfermería aplicados al donante potencial basan su fundamento científico en la teoría de Henderson, ${ }^{8}$ sobre las necesidades básicas. La monitorización respiratoria como parte de las necesidades incluye control de parámetros respiratorios, control de la saturación de oxígeno, monitorización gasométrica arterial, permeabilidad y humedad de vías áreas, aspiración de secreciones con técnica estéril contribuyendo todo esto no solo a la buena oxigenación sino como indicador de calidad de un posible trasplante pulmonar. El control de la eliminación urinaria, control de la diuresis y los de glicemia 
son elementos a tener en cuenta al hablar de necesidad de eliminación, es bueno enfatizar que la poliuria secundaria a la diabetes insípida puede provocar hipovolemia grave afectando de esta forma la perfusión de órganos y la función renal del potencial donante.

El mantenimiento de la temperatura corporal ya sea hipotermia o la hipertermia es otra necesidad que lleva intervenciones de enfermería de forma inmediata; evitar la hipotermia secundaria a la muerte es muy importante que no se afecte el metabolismo de los órganos y la función inicial de los injertos, el cadáver debe tener una temperatura superior a 35-36 grados Celsius y se aplicarán medidas como manta térmica, infusiones de sueros calientes si apareciera hipotermia, en caso de hipertermia la administración de antipiréticos y la aplicación de medidas físicas.

Las acciones de enfermería encaminadas a satisfacer la necesidad de hidratación están en la vigilancia del déficit de volumen de líquidos, las alteraciones de la perfusión tisular y el control de la presión venosa central. El control de zonas potenciales y la oclusión ocular son cuidados decisivos que realiza la enfermera y se fundamenta científicamente en la necesidad de seguridad e infecciones.

\section{Conclusión}

Dada la práctica asistencial, se conoce que existen los protocolos de atención para la preservación de órganos y tejidos en DPO, los que están descritos científicamente, sin embargo es necesario reforzar la formación profesional.

\section{Referencias Bibliográficas}

1. López Lucas MD. Manual sobre donación y trasplante de órganos, de Pascual Parrilla, Pablo Ramírez y Antonio Ríos (coords.). Editoral Arán, Madrid. 2008. Págs. 896. Enfermería Global. 2009;p. 0 - 0. Available from: http://scielo.isciii.es/scielo.php?script=sci_arttext\& pid=S1695-61412009000100024\&nrm=iso.

2. Adela Martínez Sesma, M Zabalza Ollo. Cuidados de enfermería en el mantenimiento del donante potencial de órganos en muerte encefálica. Enfermería intensiva. 2001;12(1):10-20. Available from: https://dialnet. unirioja.es/servlet/articulo? codigo $=1705848$.

3. Muñoz Camargo J. Revisión de conocimientos sobre atención de Enfermería en el trasplante de órganos y tejidos. Enfermería intensiva. 2009;20(2):76-79.
Available from: https://dialnet.unirioja.es/servlet/articulo? codigo $=1705848$.

4. Fernando Ramos Peña, Soraya de Cos Echaniz, M Plácida García Mota, Amparo Delgado Requejo, Leonor Ahedo Arrien, Ana Rosa Muñoz García, et al. Problemas de enfermería en el trasplante a pacientes añosos. Revista de la Sociedad Española de Enfermería Nefrológica. 2009;12(4):294-299.

5. Ríos A, Ramírez P, Parrilla P. Unidades trasplantadoras de órganos sólidos ante la donación de vivo. Medicina Clínica. 2006 Oct;127(15):595-596. Available from: http://linkinghub.elsevier.com/retrieve/ pii/S0025775306723429.

6. Esperanza Vélez Vélez. Donación de órganos, una perspectiva antropológica. Revista de la Sociedad Española de Enfermería Nefrológica. 2007 Sep;10(3):19-25. Available from: http://scielo.isciii.es/scielo.php?script=sci_arttext\& pid=S1139-13752007000300004.

7. Omar Martínez Mompeller, Ariadna García Rodríguez, Yosbel Ceballo Morejón, Carlos Alberto León González, Armando Martínez Fábregas. Mantenimiento del donante de órganos en muerte encefálica. Revista de Ciencias Médicas de Pinar del Río. 2005;9(1):29_ 39. Available from: http://revcmpinar.sld.cu/index.php/ publicaciones/article/view/211.

8. Henderson V. The nature of nursing: a definition and its implications for practice, research, and education: reflections after 25 years. New York: National League for Nursing Press; 1991. 